\title{
FORMULATION, DEVELOPMENT AND IN VITRO EVALUATION OF TRAMADOL EXTENDED- RELEASE TABLETS
}

\author{
SANJAY KUMAR GUPTA ${ }^{*}$, AFRAH HUNEZA², SRADHANJALI PATRA ${ }^{3}$
}

1,2Shadan College of Pharmacy, Peerancheru, Hyderabad, 500091, Telangana, ${ }^{3}$ University Department of Pharmaceutical Sciences, Utkal University, Bhubaneswar, Odisha, India

Email: snj.gupta4@gmail.com

Received: 22 Jan 2019 Revised and Accepted: 17 May 2019

\begin{abstract}
Objective: The objective of the present study was to develop "once daily" extended-release tablets of tramadol (100 mg) by wet granulation using hydrophilic polymer like hydroxypropyl methylcellulose K100M, K15M and polyethylene oxide (PEO).

Methods: The tramadol matrix tablets were prepared by using different polymers like hydroxypropyl methyl cellulose (HPMC K15M and K100M), polyethylene oxide (PEO) as the nontoxic and easily available suitable matrix system. The extended-release tablets of tramadol (400 mg) were prepared wet granulation technique. Different pre-compression and post-compression were performed. In vitro dissolution tests were performed and percentage drug release was calculated. The Fourier-transform infrared spectroscopy (FTIR) studies conducted on pure drug tramadol and the optimized formulation (T6). Different release models like zero order, first order, higuchi and Korsemeyer-Peppas were applied to in vitro drug release data in order to evaluate the drug release mechanisms and kinetics.
\end{abstract}

Results: Pre-compression and post-compression parameters satisfied with pharmacopeia specifications. The In vitro release studies were performed using USP type II apparatus showed that optimized formulation T6 consisting of polyethylene oxide (PE0) with 25 mg of the polymer was found to extended release of tramadol over a period of $24 \mathrm{~h}$. The optimized formulation T6 followed the zero-order kinetics as correlation coefficient $\left(\mathrm{r}^{2}\right)$ values are higher than that of first-order release kinetics. In order to understand the complex mechanism of drug release from the optimized formulation T6 matrix system, the in vitro release rate were fitted to Korsemeyer-Peppas model and the release exponent value (n) obtained was 0.82105 exhibited anomalous (non fickian) diffusion mechanism.

Conclusion: The present study shows that polyethylene oxide was found to play a great role in controlling release of tramadol from the matrix system. Accordingly, it can be concluded that the formulation is robust in the performance is less likely to be affected by the various factors studied.

Keywords: HPMC K100M, Polyethylene oxide, Extended-release (ER), Sustained release (SR)

(C) 2019 The Authors. Published by Innovare Academic Sciences Pvt Ltd. This is an open-access article under the CC BY license (http://creativecommons.org/licenses/by/4.0/) DOI: http://dx.doi.org/10.22159/ijpps.2019v11i7.32100

\section{INTRODUCTION}

Oral drug delivery is the largest and the oldest segment of the total drug delivery market. It is the fastest growing and most preferred route for drug administration. Increased complications and expense involved in the marketing of new drug entities have focused greater attention on the development of sustained release (SR) or controlled release (CR) or extended release (ER) drug delivery systems [1-3]. Sustained release (SR) or controlled release (CR) or extended release (ER) delivery systems can achieve predictable and reproducible release rates, extended duration of activity for short half-life drugs, decreased toxicity, and reduction of required dose, optimized therapy and better patient compliance. Sustained release (SR) or controlled release (CR) or extended release (ER) drug delivery systems are designed by different techniques like enteric coating, osmotic pump, prodrugs, transdermal patches and matrix tablets. Among the various techniques used, recently the attention of pharmaceutical researchers has been attracted by the matrix tablets. Matrix type sustained delivery systems are popular because of their ease of manufactures. It excludes complex production procedure such as coating and pelletization during manufacturing and drug release from the dosage form. It is controlled mainly by the type and proportion of the polymers used in the preparation. Hydrophilic polymer matrix system are widely used for designing oral sustained release delivery systems because of their flexibility to provide a desirable drug release profile, cost-effectiveness, and broad regulatory acceptance $[4,5]$.

Tramadol $\mathrm{HCl}(\mathrm{TmH})$ is a centrally acting opioid and nonopioid analgesic. TmH acts as an opiate agonist, through selective binding to the $\mu$-opioid receptor, and weak inhibition of norepinephrine and serotonin uptake. It is used when non-steroidal anti-inflammatory drugs (NSAIDs) fail to mitigate pain. It works in the brain to change how your body feels and responds to pain. It's also used to treat long-standing pain when weaker painkillers not work.

The aim of the study was to develop "once daily" extended-release tablets of tramadol (100 mg) for the treatment of severe acute and chronic pain. Tramadol is readily absorbed after oral administration because of tramadol belongs to BCS class I drug has a good bioavailability $68-72 \%$ and short half-life $\left(\mathrm{t}_{1 / 2}=5-6 \mathrm{~h}\right)$. It is prescribed 3-4 times a day usual dosage regimen of 50-100 mg and a maximum dose $400 \mathrm{mg}$ ( $50 \mathrm{mg} 4$ times a day). This frequent dosing schedule cause an increased incident of side effects, noncompliances and development of tolerance especially in long term used like osteoarthritis, arthritis, post-surgical pains etc. [6, 7]. It can be suggested that there is a strong clinical implication of SR formulation of this drug.

\section{MATERIALS AND METHODS}

\section{Materials}

Materials used in this study were obtained from different sources Tramadol a gift sample from Chandra lab, hyderabad. Hydroxypropyl methylcellulose (HPMC K15M and K100M), polyethylene oxide (PEO), magnesium stearate procured from ISP, Hyderabad. Microcrystalline cellulose procured from loba chemie pvt ltd, Mumbai. Talc procured from SD fine chemicals pvt ltd, Mumbai.

\section{Methods}

Preformulation studies

Preformulation is defined as the study of physical and chemical properties of a drug substance alone prior to formulation. The overall 
objective of pre-formulation studies is to generate information useful to the formulator in developing stable dosage forms [8].

\section{Colour, odour and appearance}

The drug sample was evaluated for its colour and odour. The results are shown in table 8

\section{Determination of solubility}

The solubility of drug tramadol is determined by using a different solvent like water, methanol and acetone. The result are shown in table 9.

\section{Determination of $\lambda$ max}

Standard stock solution: $100 \mathrm{mg}$ of tramadol was dissolved in a sufficient amount of methanol and makeup to $100 \mathrm{ml}$ with $0.1 \mathrm{~N} \mathrm{HCL}$ to give a concentration of $1000 \mu \mathrm{g} / \mathrm{ml}$ (stock solution A).

Scanning: From the stock solution (stock A) pippet out $1 \mathrm{ml}$ and was make up to $10 \mathrm{ml}$ to give a concentration $100 \mu \mathrm{g} / \mathrm{ml}$ (stock solution B) was prepared and UV scan was taken between 200 to $400 \mathrm{~nm}$. The absorption maximum was found to be $270 \mathrm{~nm}$ and was used for further analytical studies $[9,10]$.

\section{Calibration curve of tramadol in $0.1 \mathrm{~N} \mathrm{HCL}$}

From this stock solution dilutions were made in $0.1 \mathrm{~N} \mathrm{HCL}$ in order to get $2 \mu \mathrm{g} / \mathrm{ml}, 4 \mu \mathrm{g} / \mathrm{ml}, 6 \mu \mathrm{g} / \mathrm{ml}, 8 \mu \mathrm{g} / \mathrm{ml}, 10 \mu \mathrm{g} / \mathrm{ml}$, the absorbance of these solutions were measured at $\lambda$ max $270 \mathrm{~nm}$ using UV-visible spectrophotometer and the standard curve was plotted. The linearity plot was obtained for the aliquot concentration of $2,4,6,8$; $10 \mu \mathrm{g} / \mathrm{ml}$ with the absorbance was seen at $270 \mathrm{~nm}$.

\section{Calibration curve of tramadol in pH 6.8 phosphate buffer}

Standard Stock solution: $100 \mathrm{mg}$ of tramadol was dissolved in a sufficient amount of ethanol and makeup to $100 \mathrm{ml}$ of pH6.8 phosphate buffer to give a concentration of $1000 \mu \mathrm{g} / \mathrm{ml}$ (stock solution A). From the stock solution (stock A) pippet out $1 \mathrm{ml}$ and was make up to $10 \mathrm{ml}$ to give a concentration $100 \mu \mathrm{g} / \mathrm{ml}$ (stock solution B), from this stock solution subsequent dilutions were made in phosphate buffer $\mathrm{pH} 6.8$ in order to get $2 \mu \mathrm{g} / \mathrm{ml}, 4 \mu \mathrm{g} / \mathrm{ml}, 6 \mu \mathrm{g} / \mathrm{ml}, 8 \mu \mathrm{g} / \mathrm{ml}, 10 \mu \mathrm{g} / \mathrm{ml}$, absorbance of these solutions were measured at $\lambda \max 270 \mathrm{~nm}$ using uv-visible spectrophotometer and standard curve was plotted. The linearity plot was obtained for the aliquot concentration of $2,4,6,8 ; 10 \mu \mathrm{g} / \mathrm{ml}$ with the absorbance was seen at $270 \mathrm{~nm}$ [11-14].

\section{Drug-excipient compatibility study}

Infrared spectroscopy is a useful analytical technique utilized to check the chemical interaction between the drug and excipients used in the formulation.1-2 mg of solid fine powder of drug tramadol and 200-300 mg of dry powder of $\mathrm{KBr}$ (IR grade) were taken in a mortar and mixed well with the help of a spatula. Spectrum measurement was carried out using $\mathrm{KBr}$ disk method in the wavelength region of $4000-400 \mathrm{~cm}-1$ by FTIR spectrophotometer [15-16]. The IR spectrum of the physical mixture was compared with that of the pure drug to check any possible drug-excipient interaction. The spectrum of FT-IR is shown in fig. 4 and 5.

\section{Formulation of an extended-release tablet}

In the formulations prepared, the release retardants included were hydroxyl propyl methyl cellulose (HPMC K15M, HPMC K100M CR), polyethylene oxide (PEO) and microcrystalline cellulose (MCC), magnesium stearate (MS) $1 \%$ and talc $2 \%$ were used as lubricants. $5 \%$ $\mathrm{w} / \mathrm{v}$ solution of polyvinyl pyrrolidone (PVP-K30) in isopropyl alcohol (IPA) was used as a binder. Compositions of different formulations were given in the following tables no 1-3. Microcrystalline cellulose, PVP K30 were weighed according to the given table and sifted through 40 mesh. To the above blend tramadol was added and sifted through 18 mesh. The sifted materials were mixed for $10 \mathrm{~min}$. Magnesium stearate and talc were weighed and sifted through 40 mesh. To the powdered blend, the lubricated blend was added and mixed properly. Then the total blend was used for Pre-compression parameters and then compressed using 8 mm round punches [17-20].

\section{Pre-compression parameters}

The following pre-compression parameter was evaluated like bulk density and tapped density, angle of repose, Hausner's ratio and compressibility index (\%).

Table 1: Composition of matrix tablets containing HPMC K15M

\begin{tabular}{llll}
\hline Ingredients (mg) & Formulation code & & \\
\cline { 2 - 4 } & T1 & T2 & \\
\hline Tramadol & 100 & 100 & T3 \\
HPMC K15M & 12.25 & 25 & 100 \\
MCC & Qs & qs & 50 \\
PVP-K90 & 6 & 6 & qs \\
IPA & Qs & qs & qs \\
Mg stearate & 1.2 & 1.2 & qs \\
Talc & 2.4 & 2.4 & 1.2 \\
Total weight & 400 & 400 & 2.4 \\
\hline
\end{tabular}

*qs = quantity sufficient

Table: 2 Composition of matrix tablets containing polyethylene oxide

\begin{tabular}{lllll}
\hline Ingredients (mg) & Formulation code & & & \\
\cline { 2 - 5 } & T5 & T6 & T7 & T8 \\
\hline Tramadol & 100 & 100 & 100 & 100 \\
Polyethylene oxide & 12.25 & 25 & 50 & 100 \\
MCC & Qs & qs & qs & qs \\
PVP-K90 & 6 & 6 & 6 & 6 \\
IPA & Qs & qs & qs & qs \\
Mg stearate & 1.2 & 1.2 & 1.2 & 1.2 \\
Talc & 2.4 & 2.4 & 2.4 & 2.4 \\
Total weight & 400 & 400 & 400 & 400 \\
\hline
\end{tabular}

*qs = quantity sufficient 
Table 3: Composition of matrix tablets containing HPMC K100M

\begin{tabular}{llll}
\hline Ingredients (mg) & Formulation code & & \\
\cline { 2 - 4 } & T9 & T10 & \\
\hline Tramadol & 100 & 100 & T11 \\
HPMC K100M & 12.25 & 25 & 100 \\
MCC & Qs & qs & 50 \\
PVP-K90 & 6 & 6 & qs \\
IPA & Qs & qs & qs \\
Mg stearate & 1.2 & 100 & qs \\
Talc & 2.4 & 2.4 & 1.2 \\
Total weight & 400 & 400 & 2.4 \\
\hline
\end{tabular}

$*_{\text {qs }}=$ quantity sufficient

\section{Bulk density and tapped density}

Both loose bulk density (LBD) and tapped bulk density (TBD) were determined. First $25 \mathrm{gm}$ of the blend from each formulation was weight accurately and kept into a cleaned dried $50 \mathrm{ml}$ graduated measuring cylinder. After than initial volume was noted is called as bulk volume and the bulk density is calculated by the following formula [21-22]. The results are given in the table 13.

Bulk density $=$ Weight of blend (gram) $/$ Bulk volume of the blend

After measuring bulk volume the same measuring cylinder subject to 500 tap with the help of bulk density measuring Apparatus. The tapped volume occupied by the powder is recorded. Then the tapped density is measured by the following formula. The outcomes are given in the table 13 .

$$
\text { Tapped density }=\frac{\text { Weight of blend(gram) }}{\text { Tapped volume }}
$$

\author{
Angle of repose \\ $\operatorname{Tan} \theta=\mathrm{h} / \mathrm{r}$ \\ $\theta=\tan ^{-1}(\mathrm{~h} / \mathrm{r})$ \\ Where, \\ $\theta=$ Angle of repose \\ $\mathrm{h}=$ Height of the powder cone \\ $\mathrm{r}=$ Average radius of the powder cone
}

The angle of repose of powdered blend was determined by the funnel method. The accurately weight $15 \mathrm{gm}$ powdered blend was taken in the funnel. The height of the funnel was adjusted in such a way that the tip of the funnel just touched the apex of the blend. The powdered blend was allowed to flow through the funnel freely on to the surface. The diameter of the powder cone was measured and the angle of repose was calculated using the following equation [23, 24].

Table 4: Relationship between the angle of repose and powder flow

\begin{tabular}{lll}
\hline S. No. & Angle of repose & Flow property \\
\hline 1 & $<25$ & Excellent \\
2 & $25-30$ & Good \\
3 & $30-40$ & Passable \\
4 & 40 and above & Very poor \\
\hline
\end{tabular}

\section{Hausner's ratio}

Hausner's ratio is an indirect index of ease of powder flow which is calculated by the following formula. The outcomes are given in the table 12

\section{Compressibility index (\%)}

It is also one of the simple methods to evaluate flow property of powder by comparing the bulk density and tapped density is calculated by the following formula [25-27]. The outcomes are given in the table 12

$$
\text { Carr's index }=\frac{(\text { Tapped density }- \text { bulk density })}{\text { Tapped density }} \times 100
$$

Table 5: Relationship between Hausner's ratio and powder flow

\begin{tabular}{ll}
\hline Flow character & Hausner ratio \\
\hline Excellent & $1.00-1.11$ \\
Good & $1.12-1.18$ \\
Fair & $1.19-1.25$ \\
Passable & $1.26-1.34$ \\
Poor & $1.35-1.45$ \\
Very Poor & $1.46-1.59$ \\
Very, Very Poor & $>1.60$ \\
\hline
\end{tabular}

Table 6: Relationship belongings compressibility index and powder flow

\begin{tabular}{lll}
\hline S. No. & Compressibility Index (\%) & Flow property \\
\hline 1 & $5-15$ & Excellent \\
2 & $12-16$ & Good \\
3 & $18-21$ & Passable \\
4 & $23-35$ & Poor \\
5 & $33-38$ & Very poor \\
6 & $<40$ & Very very poor \\
\hline
\end{tabular}




\section{Evaluations of the tablet}

\section{Thickness}

The thickness of the tablets is measured by vernier calipers and it is expressed in mm. Tablet thickness should be controlled within $a \pm 5 \%$ variation of standard value the outcomes are given in table 13 .

\section{Hardness}

Tablets require strength or hardness to withstand mechanical shocks of handling in the manufacture, packing and shipping. Tablet hardness was measured by monsanto hardness tester and results are expressed in $\mathrm{Kg} / \mathrm{cm}^{2}$. The outcome are given in the table 13

\section{Weight variation test}

20 tablets were weighed individually. Average weight was calculated from the total weight of all tablets. The individual weights were compared with the average weight. The percentage difference in the weight variation should be within the permissible limits $( \pm 5 \%)$. The percent deviation was calculated using the following formula. The acceptance limits are as per United States pharmacopeia (USP) [28]. The outcome are given in the table 13

Table 7: Limits for tablet weight variation test (USP)

\begin{tabular}{ll}
\hline Average weight of tablet (mg) & \% Difference allowed \\
\hline 130 or less & $10 \%$ \\
From 130 to 324 & $7.5 \%$ \\
$>324$ & $5 \%$ \\
\hline
\end{tabular}

\section{Friability}

It was performed in roche friabilator where the tablets were subjected to the combined effect of abrasion and shock by utilizing a plastic chamber that revolves at $25 \mathrm{rpm}$ dropping the tablets at a distance of six inches with each revolution in the chamber. Preweighted samples of 20 tablets were placed in the friabilator, which is then operated for 100 revolutions. The tablets are then dusted and reweighed. Permitted friability limit is $1.0 \%$. The percent friability was determined using the following formula [29-30].

$$
\begin{aligned}
& \text { (Initial weight-final weight } \\
& \% \text { Friability }=\text { Initial weight } \quad \text { X100 }
\end{aligned}
$$

\section{Drug content uniformity}

The content uniformity test is used to ensure that every tablet contains the amount of drug substance intended with little variation among tablets within a batch. Randomly 30 tablets were selected from which 10 tablets were taken and triturated well in a mortar. The quantity equivalent to $100 \mathrm{mg}$ of tramadol was dissolved in 100 $\mathrm{ml}$ of phosphate buffer $\mathrm{pH} 6.8$ solutions on a rotary shaker overnight. The absorbance was measured using UV-Visible spectrophotometer at $270 \mathrm{~nm}$ [31-32]. The outcomes are given in the table 13.

\section{In vitro dissolution studies}

The dissolution rate of extended-release tablets from all formulations was performed using LAB INDIA dissolution apparatus (USP II) with paddle. The dissolution fluid was $900 \mathrm{ml} 0.1 \mathrm{~N}$ HCL for first $2 \mathrm{~h}$ then replaced with phosphate buffer $\mathrm{pH} 6.8$ at a speed of 50 rpm and a temperature of $37 \pm 0.5{ }^{\circ} \mathrm{C}$ were used in each test. The dissolution experiments were conducted in triplicate. For all tests 5 $\mathrm{ml}$ samples of the test medium were collected at set intervals $(1,2,4$, $6,8,12,18$ and $24 \mathrm{~h}$ ) and were replaced with equal volume of phosphate buffer $\mathrm{pH}$ 6.8. The samples were analyzed at $270 \mathrm{~nm}$ using a UV spectrophotometer [33-35].

\section{Kinetic analysis of dissolution data}

In order to determine the release mechanism that provides the best description to the pattern of drug release, the in vitro release data were fitted to zero-order, first-order, hixson crowell, and Korsemeyer-Peppas model [36-37]. The data of the regression coefficient of different kinetic models were summarized in table 17.

\section{RESULTS}

Preformulation study: These test results were illustrated below

Table 8: table showing the description of tramadol (API)

\begin{tabular}{ll}
\hline Test & Description \\
\hline Colour & White or almost white crystalline powder \\
Odour & Free of odour \\
\hline
\end{tabular}

Solubility: These tests results were illustrated below

Table 9: Solubility of tramadol (API) in various solvents

\begin{tabular}{ll}
\hline Solvents & Solubility \\
\hline Water & Freely soluble \\
Methanol & Freely soluble \\
Acetone & Slightly soluble \\
\hline
\end{tabular}

\section{Preparation of standard calibration curve of tramadol}

\section{Standard graph of tramadol in $0.1 \mathrm{~N} \mathrm{HCl}$}

In the pre-formulation study, it was found that the $\lambda$ max of tramadol by the spectrophotometric method in phosphate buffer $0.1 \mathrm{~N} \mathrm{HCL}$ was found to be $270 \mathrm{~nm}$. The spectrum was shown in fig.

\section{Drug and excipients compatibility studies}

FTIR studies conducted on pure drug tramadol and the optimize formulation (T6) given in fig. 4 and 5, which showed that there is no marked interaction between drug and excipients used.

\section{Characterization of tramadol powder blend}

The blends for tramadol tablets were characterized with respect to the angle of repose, bulk density, tapped density, carr's index, and hausner's ratio. Angle of repose was between $22.7^{\circ}$ to $28.5^{\circ}$ and carr's index values were less than 15 for the blend of all the batches indicating excellent to good flowability and compressibility. Hausner's ratio was less than 1.25 for all the batches indicating excellent flow properties. The results were summarized in table 12 .

\section{Evaluation of physical parameter}

The physical properties of tramadol extended-release tablets were given in table 13 . Tablet thickness should be controlled within $a \pm 5 \%$ 
variation of standard value. The prepared tablets in all the formulations possessed good mechanical strength with sufficient hardness in the range of $6.0 \pm 0.21$ to $6.7 \pm 0.41 \mathrm{~kg} / \mathrm{cm}^{2}$. Friability values below $1 \%(0.32 \pm 0.62-0.42 \pm 0.42 \%)$ were an indication of good mechanical resistance of the tablets. All the tablets from each formulation passed weight variation test, as the \% weight variation was within the pharmacopoeial limits of $\pm 5 \%$ of the weight. The weight variation in all the formulations was found to be $398 \pm 1.56$ to $409 \pm 1.23 \mathrm{mg}$, which was in pharmacopoeial limits of $\pm 5 \%$ of the average weight. The percentage drug content of all the tablets was found to be between $98.2 \pm 0.66 \%$ to $103 \pm 0.68 \%$ of Tramadol which was within the acceptable limits.

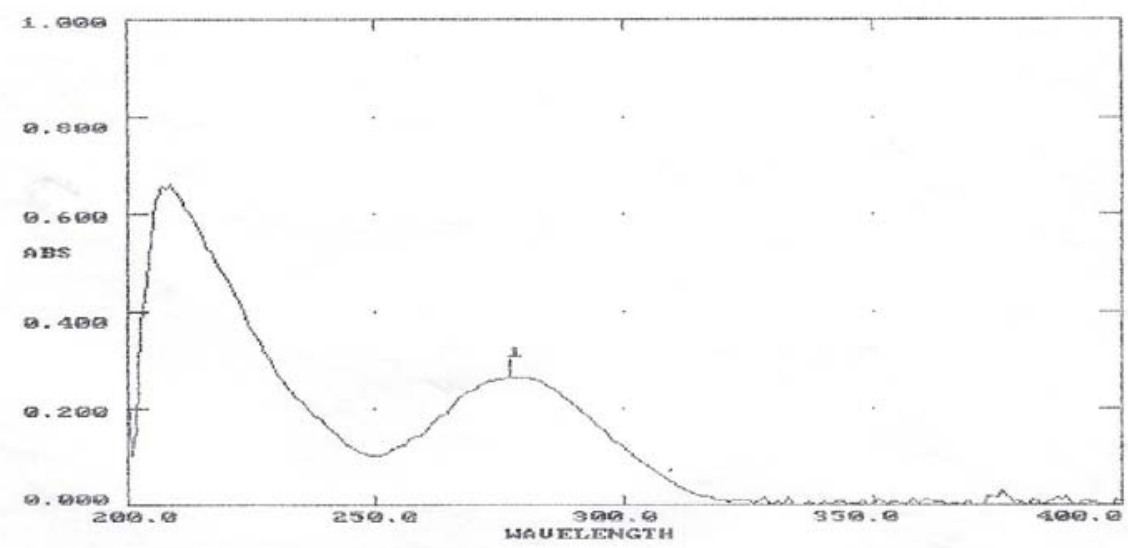

Fig. 1: $\lambda \max$ of tramadol

Table 10: Concentration and absorbance of tramadol in $0.1 \mathrm{~N} \mathrm{HCl}$

\begin{tabular}{ll}
\hline Concentration & Absorbance at 271 nm \\
\hline 0 & 0 \\
20 & 0.126 \\
40 & 0.227 \\
60 & 0.359 \\
80 & 0.467 \\
100 & 0.572 \\
120 & 0.689 \\
\hline
\end{tabular}

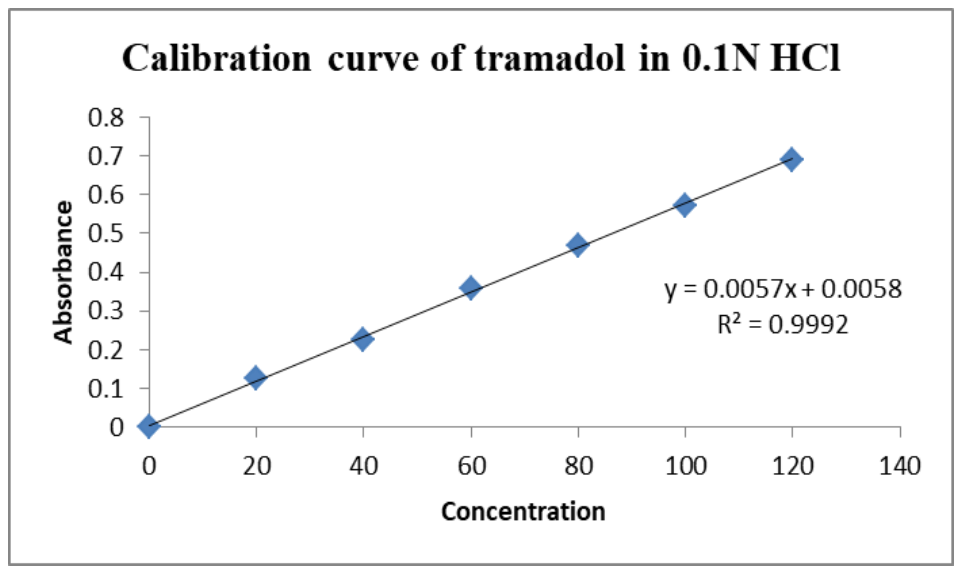

Fig. 2: Calibration curve of tramadol in 0.1N HCL

Table 11: Concentration and absorbance of tramadol in pH 6.8 phosphate buffer

\begin{tabular}{ll}
\hline Concentration & Absorbance at 271 nm \\
\hline 0 & 0 \\
20 & 0.172 \\
40 & 0.283 \\
60 & 0.399 \\
80 & 0.523 \\
100 & 0.645 \\
120 & 0.791 \\
\hline
\end{tabular}




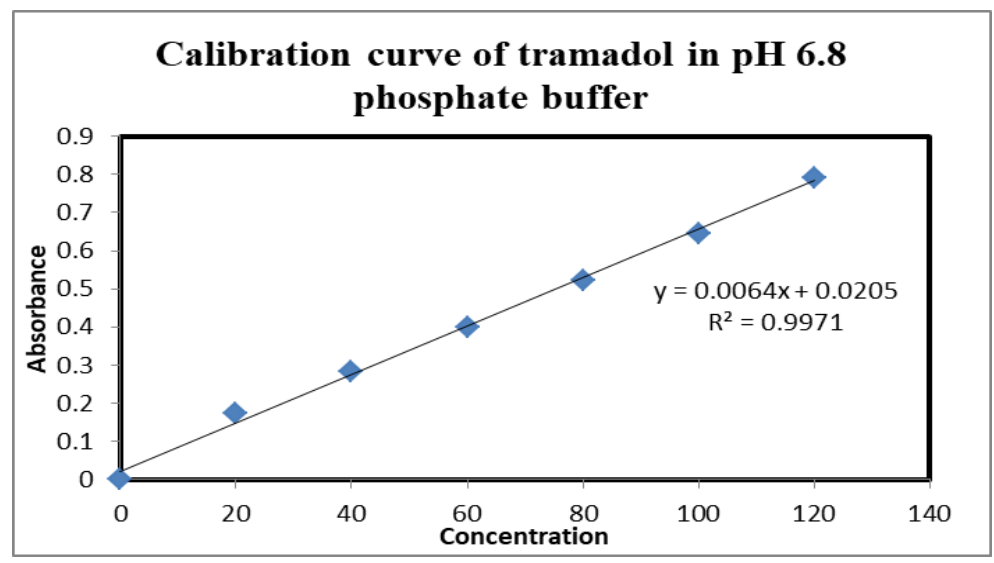

Fig. 3: Calibration curve of tramadol in pH 6.8 phosphate buffer

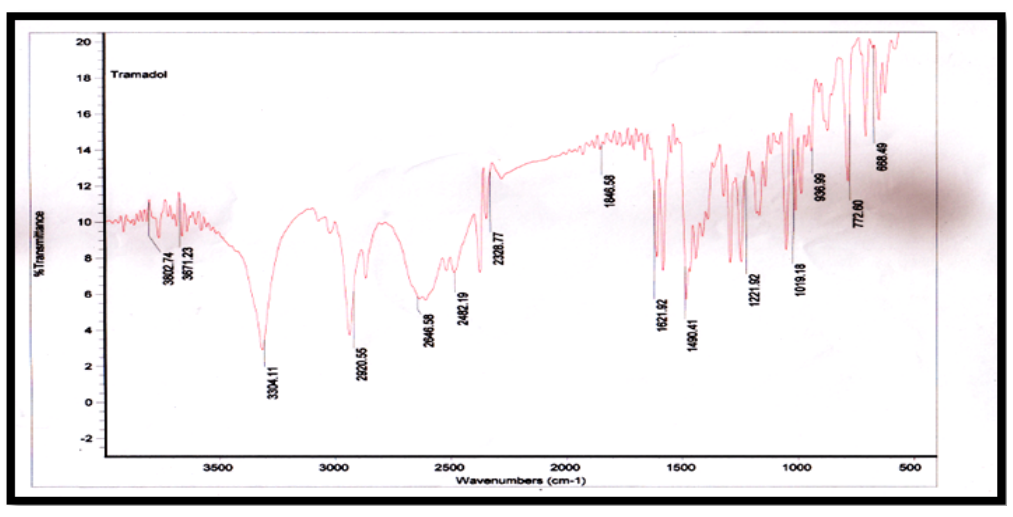

Fig. 4: FTIR spectra of tramadol pure drug

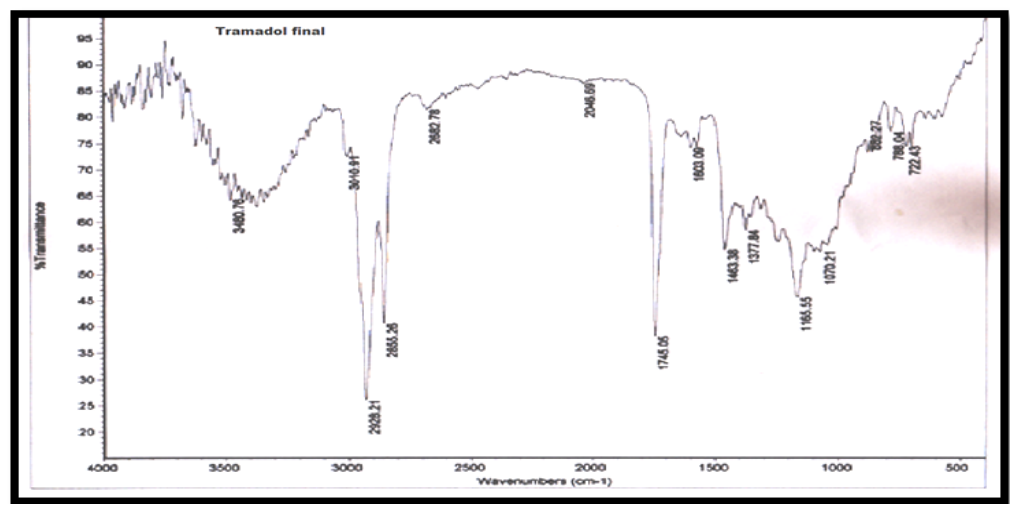

Fig. 5: FTIR Spectra of tramadol optimized formulation

Table 12: Preformulation parameters of tramadol matrix tablets

\begin{tabular}{|c|c|c|c|c|c|c|}
\hline S. No. & Formulations & $\begin{array}{l}\text { Bulk density } \\
(\mathrm{gm} / \mathrm{ml})^{*}\end{array}$ & $\begin{array}{l}\text { Tapped density } \\
(\mathrm{gm} / \mathrm{ml})^{*}\end{array}$ & $\begin{array}{l}\text { Compressibility } \\
\text { Index }(\%)^{*}\end{array}$ & Angle of repose ${ }^{*}$ & $\begin{array}{l}\text { Hausner's } \\
\text { ratio* }\end{array}$ \\
\hline 1 & $\mathrm{~T} 1$ & $0.43 \pm 0.022$ & $0.49 \pm 0.060$ & $12.24 \pm 1.38$ & $22.7^{\circ} \pm 0.21$ & $1.13 \pm 0.021$ \\
\hline 2 & $\mathrm{~T} 2$ & $0.41 \pm 0.029$ & $0.47 \pm 0.021$ & $12.76 \pm 2.52$ & $25.7^{\circ} \pm 0.45$ & $1.14 \pm 0.024$ \\
\hline 3 & T3 & $0.46 \pm 0.019$ & $0.53 \pm 0.035$ & $13.20 \pm 1.15$ & $26.1^{\circ} \pm 0.32$ & $1.15 \pm 0.023$ \\
\hline 4 & $\mathrm{~T} 4$ & $0.44 \pm 0.021$ & $0.51 \pm 0.024$ & $13.72 \pm 2.63$ & $25.9^{\circ} \pm 0.44$ & $1.15 \pm 0.015$ \\
\hline 5 & T5 & $0.40 \pm 0.036$ & $0.47 \pm 0.028$ & $14.89 \pm 1.69$ & $24.3^{\circ} \pm 0.26$ & $1.17 \pm 0.021$ \\
\hline 6 & T6 & $0.37 \pm 0.012$ & $0.43 \pm 0.011$ & $13.95 \pm 0.98$ & $26.6^{\circ} \pm 0.16$ & $1.16 \pm 0.011$ \\
\hline 7 & $\mathrm{~T} 7$ & $0.41 \pm 0.052$ & $0.48 \pm 0.021$ & $14.58 \pm 1.35$ & $25.5^{\circ} \pm 0.50$ & $1.17 \pm 0.021$ \\
\hline 8 & $\mathrm{~T} 8$ & $0.34 \pm 0.045$ & $0.39 \pm 0.028$ & $12.82 \pm 1.45$ & $24.9^{\circ} \pm 1.39$ & $1.14 \pm 0.021$ \\
\hline 9 & T9 & $0.38 \pm 0.032$ & $0.44 \pm 0.041$ & $13.63 \pm 2.48$ & $26.6^{\circ} \pm 0.35$ & $1.15 \pm 0.023$ \\
\hline 10 & $\mathrm{~T} 10$ & $0.33 \pm 0.028$ & $0.38 \pm 0.015$ & $13.15 \pm 2.36$ & $28.5^{\circ} \pm 0.47$ & $1.15 \pm 0.021$ \\
\hline 11 & $\mathrm{~T} 11$ & $0.40 \pm 0.024$ & $0.47 \pm 0.018$ & $14.89 \pm 1.77$ & $24.3^{\circ} \pm 0.78$ & $1.17 \pm 0.024$ \\
\hline 12 & $\mathrm{~T} 12$ & $0.37 \pm 0.063$ & $0.43 \pm 0.025$ & $13.95 \pm 1.65$ & $26.6^{\circ} \pm 0.66$ & $1.16 \pm 0.029$ \\
\hline
\end{tabular}

*Average of three observations $(n=3),{ }^{*}$ All the values are expressed as mean \pm SD 
Table 13: Post formulation parameters of tramadol matrix tablets

\begin{tabular}{|c|c|c|c|c|c|}
\hline Formulation code & Hardness $\left(\mathrm{Kg} / \mathrm{cm}^{2}\right)^{*}$ & Weight variation (mg)* & Thickness (mm)* & Friability (\%)* & Drug content $(\%)^{*}$ \\
\hline T1 & $6.0 \pm 0.21$ & $401 \pm 1.13$ & $2.22 \pm 0.033$ & $0.35 \pm 0.55$ & $99.7 \pm 0.85$ \\
\hline $\mathrm{T} 2$ & $6.6 \pm 0.32$ & $409 \pm 1.23$ & $2.12 \pm 0.086$ & $0.32 \pm 0.62$ & $103.7 \pm 0.44$ \\
\hline T3 & $6.1 \pm 0.41$ & $400 \pm 1.22$ & $2.20 \pm 0.019$ & $0.34 \pm 0.28$ & $99.4 \pm 0.64$ \\
\hline $\mathrm{T} 4$ & $6.2 \pm 0.23$ & $398 \pm 1.56$ & $2.19 \pm 0.086$ & $0.37 \pm 0.26$ & $101 \pm 0.86$ \\
\hline T5 & $6.4 \pm 0.22$ & $401 \pm 1.24$ & $2.15 \pm 0.037$ & $0.33 \pm 0.65$ & $98.6 \pm 2.19$ \\
\hline T6 & $6.3 \pm 0.22$ & $400 \pm 0.98$ & $2.17 \pm 0.011$ & $0.42 \pm 0.42$ & $103 \pm 0.68$ \\
\hline $\mathrm{T} 7$ & $6.5 \pm 0.42$ & $399 \pm 1.44$ & $2.14 \pm 0.067$ & $0.39 \pm 0.25$ & $99.5 \pm 0.52$ \\
\hline T8 & $6.7 \pm 0.41$ & $401 \pm 0.99$ & $2.11 \pm 0.069$ & $0.34 \pm 0.86$ & $98.2 \pm 0.66$ \\
\hline T9 & $6.4 \pm 0.21$ & $400 \pm 1.55$ & $2.16 \pm 0.073$ & $0.42 \pm 0.22$ & $101 \pm 0.49$ \\
\hline $\mathrm{T} 10$ & $6.5 \pm 0.26$ & $399 \pm 1.36$ & $2.13 \pm 0.031$ & $0.38 \pm 0.55$ & $99.3 \pm 0.91$ \\
\hline $\mathrm{T} 11$ & $6.5 \pm 0.28$ & $399 \pm 1.91$ & $2.14 \pm 0.088$ & $0.39 \pm 0.59$ & $99.5 \pm 0.72$ \\
\hline $\mathrm{T} 12$ & $6.2 \pm 0.39$ & $398 \pm 1.83$ & $2.19 \pm 0.061$ & $0.37 \pm 0.34$ & $102.5 \pm 0.62$ \\
\hline
\end{tabular}

*Average of three observations $(n=3),{ }^{*}$ All the values are expressed as mean \pm SD

\section{In vitro dissolution study}

In vitro drug release studies in $0.1 \mathrm{~N} \mathrm{HCl}$ (First $2 \mathrm{~h}$ ) and $6.8 \mathrm{pH}$ phosphate buffer show drug release from range $92.3 \pm 0.23 \%$ to $100.2 \pm 1.36 \%$ all formulation. The plots of $\%$ aggregate Tramadol release versus time ( $\mathrm{min}$ ) were plotted and delineated as appeared in fig. 7. The formulation T6 indicated a higher release rate of $100.2 \%$ In $24 \mathrm{H}$. uncovering that formulation made with convergences of PEO $50 \mathrm{mg}$, T6 was picked as the improved formulation.

Table 14: Dissolution data of formulation HPMC K15M (T1-T4)

\begin{tabular}{|c|c|c|c|c|}
\hline Time (h) & T1(\% of drug release)* & T2 (\% of drug release)* & T3 (\% of drug release)* & T4 (\% of drug release)* \\
\hline 1 & $36.1 \pm 0.24$ & $17.5 \pm 0.95$ & $21 \pm 0.33$ & $35.7 \pm 0.33$ \\
\hline 2 & $42.4 \pm 0.55$ & $21.8 \pm 0.22$ & $29.4 \pm 0.73$ & $44.0 \pm 0.45$ \\
\hline 3 & $63.7 \pm 0.33$ & $25.6 \pm 0.73$ & $48.9 \pm 0.92$ & $56.1 \pm 0.49$ \\
\hline 4 & $78.9 \pm 0.99$ & $59.4 \pm 0.71$ & $54.8 \pm 0.37$ & $68.8 \pm 0.50$ \\
\hline 6 & $86.3 \pm 0.25$ & $78.4 \pm 0.49$ & $74.5 \pm 0.97$ & $76.3 \pm 0.54$ \\
\hline 8 & $92.3 \pm 0.23$ & $89.6 \pm 0.97$ & $86.8 \pm 0.92$ & $82.5 \pm 0.69$ \\
\hline 12 & -- & $99.2 \pm 1.72$ & $95.4 \pm 1.22$ & $89.5 \pm 0.88$ \\
\hline 16 & -- & -- & $99.8 \pm 1.47$ & $95.6 \pm 1.2$ \\
\hline 20 & -- & -- & -- & $99.6 \pm 1.25$ \\
\hline 24 & -- & -- & -- & -- \\
\hline
\end{tabular}

*Average of three observations $(n=3),{ }^{*}$ All the values are expressed as mean \pm SD

Table 15: Dissolution data of formulation containing polyethylene oxide (T5-T8)

\begin{tabular}{|c|c|c|c|c|}
\hline Time(h) & T5(\% of drug release) ${ }^{*}$ & T6(\% of drug release) ${ }^{*}$ & T7 (\% of drug release)* & T8(\% of drug release) $)^{*}$ \\
\hline 1 & $19.8 \pm 0.27$ & $20.6 \pm 0.22$ & $14.3 \pm 0.28$ & $18.4 \pm 0.29$ \\
\hline 2 & $27.3 \pm 0.38$ & $29.3 \pm 0.33$ & $26.4 \pm 0.37$ & $34.8 \pm 0.37$ \\
\hline 3 & $38.4 \pm 0.49$ & $36.8 \pm 0.48$ & $58.5 \pm 0.42$ & $56.1 \pm 0.47$ \\
\hline 4 & $45.9 \pm 0.44$ & $44.2 \pm 0.49$ & $98.6 \pm 0.48$ & $72.2 \pm 0.59$ \\
\hline 6 & $56.4 \pm 0.56$ & $59.1 \pm 0.56$ & -- & $97.8 \pm 0.78$ \\
\hline 8 & $68.1 \pm 0.59$ & $64.1 \pm 0.59$ & -- & -- \\
\hline 12 & $77.3 \pm 0.88$ & $76.5 \pm 0.66$ & -- & -- \\
\hline 16 & $89.4 \pm 1.99$ & $92.4 \pm 0.69$ & -- & -- \\
\hline 20 & $99.8 \pm 1.25$ & $97.1 \pm 1.29$ & -- & -- \\
\hline 24 & -- & $100.2 \pm 1.36$ & -- & -- \\
\hline
\end{tabular}

*Average of three observations $(n=3), *$ All the values are expressed as mean \pm SD

Table 16: Dissolution data of formulation containing HPMC K100M (T9-T12)

\begin{tabular}{|c|c|c|c|c|}
\hline Time (h) & T9(\% of drug release) $)^{*}$ & T10 (\% of drug release) & T11(\% of drug release) ${ }^{*}$ & T12(\% of drug release) \\
\hline 1 & $38.7 \pm 0.28$ & $25.0 \pm 0.75$ & $28.2 \pm 0.92$ & $20.0 \pm 0.31$ \\
\hline 2 & $41.0 \pm 0.37$ & $34.1 \pm 0.95$ & $35.6 \pm 0.48$ & $30.4 \pm 0.73$ \\
\hline 3 & $79.5 \pm 0.48$ & $46.9 \pm 0.96$ & $48.2 \pm 0.99$ & $49.9 \pm 0.92$ \\
\hline 4 & $99.2 \pm 0.88$ & $57.2 \pm 0.47$ & $55.6 \pm 1.25$ & $56.8 \pm 0.52$ \\
\hline 6 & -- & $63.3 \pm 0.88$ & $62.4 \pm 1.76$ & $68.3 \pm 0.94$ \\
\hline 8 & -- & $70 \pm 0.82$ & $79.3 \pm 1.8$ & $82.5 \pm 1.21$ \\
\hline 12 & -- & $99.4 \pm 0.89$ & $86.2 \pm 1.9$ & $90.2 \pm 0.97$ \\
\hline 16 & -- & -- & $99.5 \pm 1.9$ & $95.5 \pm 0.73$ \\
\hline 20 & -- & -- & -- & $99.8 \pm 0.46$ \\
\hline 24 & -- & -- & -- & -- \\
\hline
\end{tabular}

*Average of three observations $(n=3),{ }^{*}$ All the values are expressed as mean \pm SD 


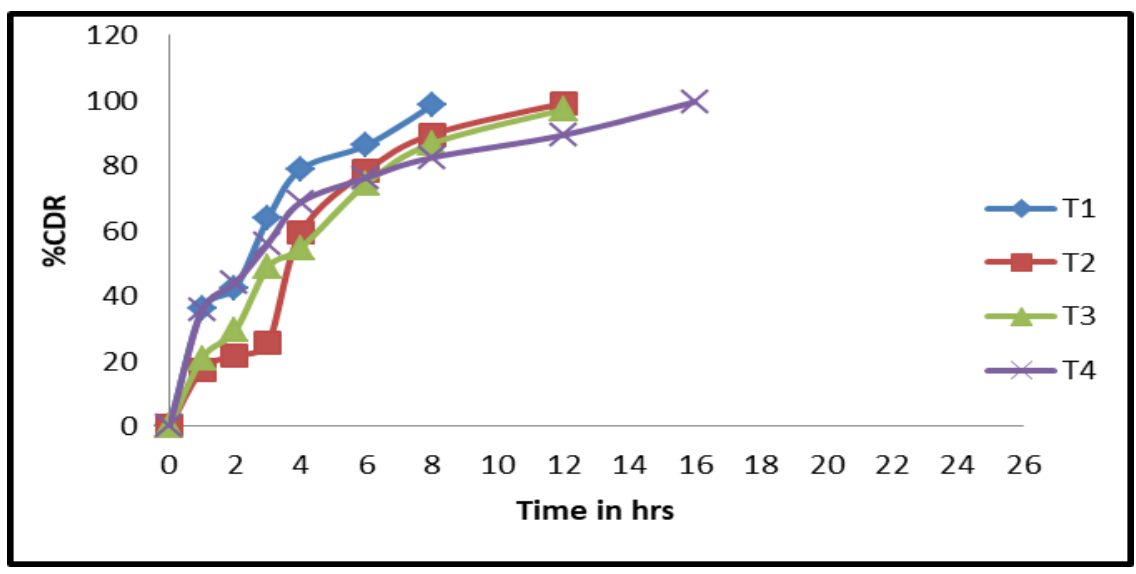

Fig. 6: Dissolution profile of formulations T1-T4

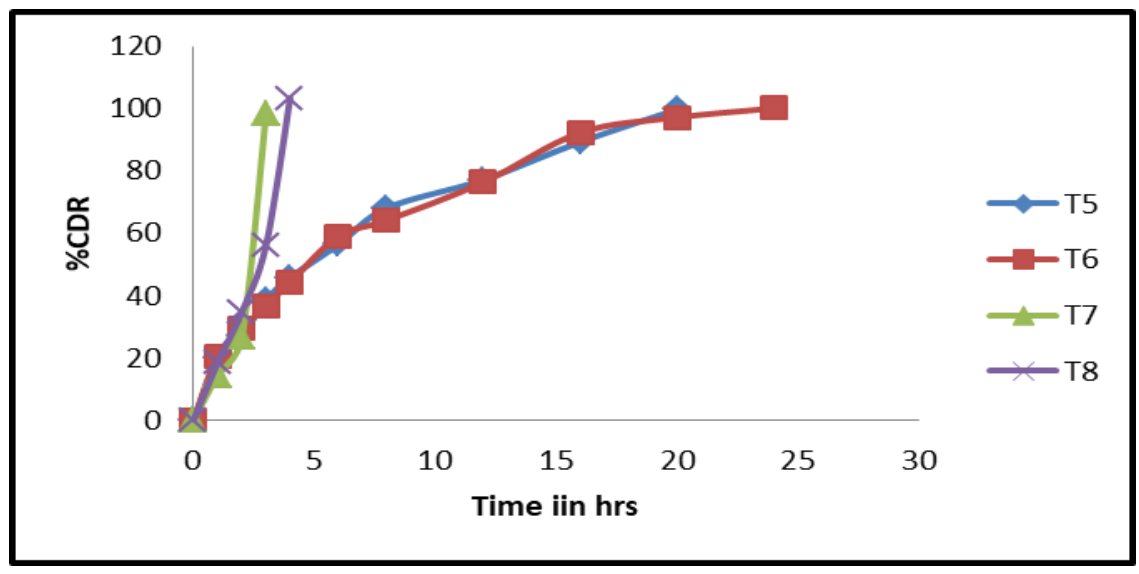

Fig. 7: Dissolution profile of formulations T5-T8

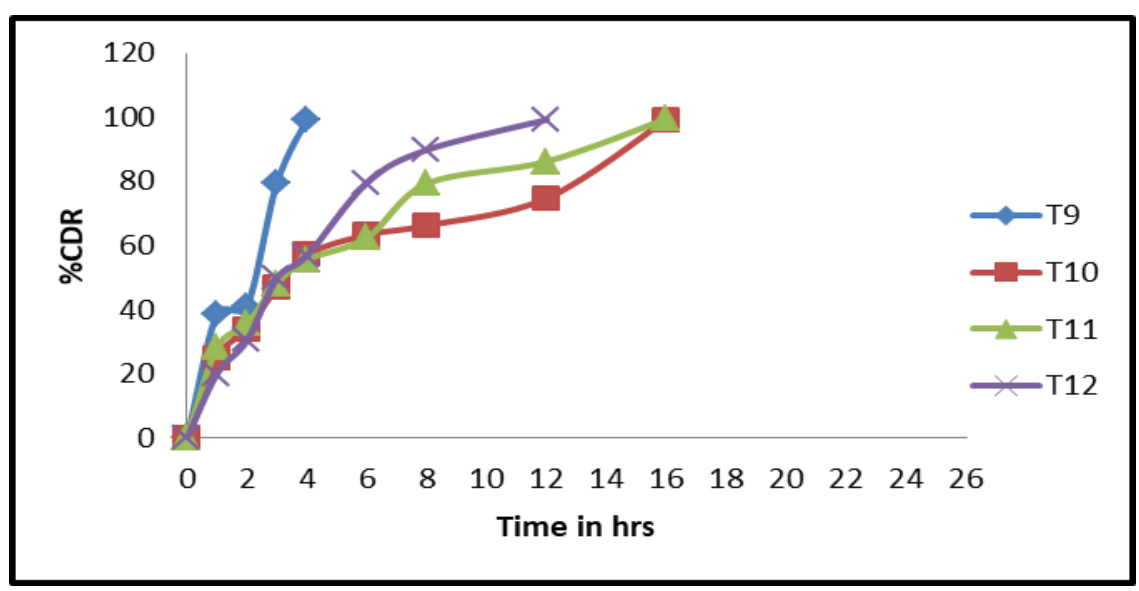

Fig. 8: Dissolution profile of formulations T9-T12

\section{Kinetic studies for optimized formulation}

For analyzing the release mechanism, the data obtained were fitted to various kinetic equations of Zero order, First order, Higuchi model and Korsmeyer-Peppas model. The regression coefficient was calculated. It was concluded that the optimized formulations T6 follows zero order kinetics as correlation coefficient $\left(\mathrm{r}^{2}\right)$ values are higher than that of first-order release kinetics. In order to understand the complex mechanism of drug release from the matrix system, the in vitro release rate were fitted to korsmeyer-peppas model and interpretation of release exponent value (n) enlighten in understanding the release mechanism from the dosage form. The release exponent value (n) obtained was 0.82105 . The T6 formulation exhibited anomalous (nonfickian) diffusion mechanism. Kinetic studies shows that the amount of drug from the matrix system was by both diffusion and erosion. There is a good scope for the development of extended-release tablets for this drug. The data of the regression coefficient of different kinetic models were summarized in table 17. 
Table 17: Release kinetics for the optimized formulation T6

\begin{tabular}{llll}
\hline & Zero & First & Higuchi \\
\hline & \% CDR Vs T & Log \% drug Remain Vs Time & \%CDR Vs $\sqrt{\text { T }}$ \\
\hline Slope & 4.227962963 & -0.063258255 & 21.3693521 \\
Intercept & 0.833641975 & 2.166610516 & -16.87673946 \\
Correlation & 0.996837882 & -0.923901295 & 0.821051124 \\
$\mathrm{R}^{2}$ & 0.993685763 & 0.853593602 & 0.419307821 \\
\hline
\end{tabular}

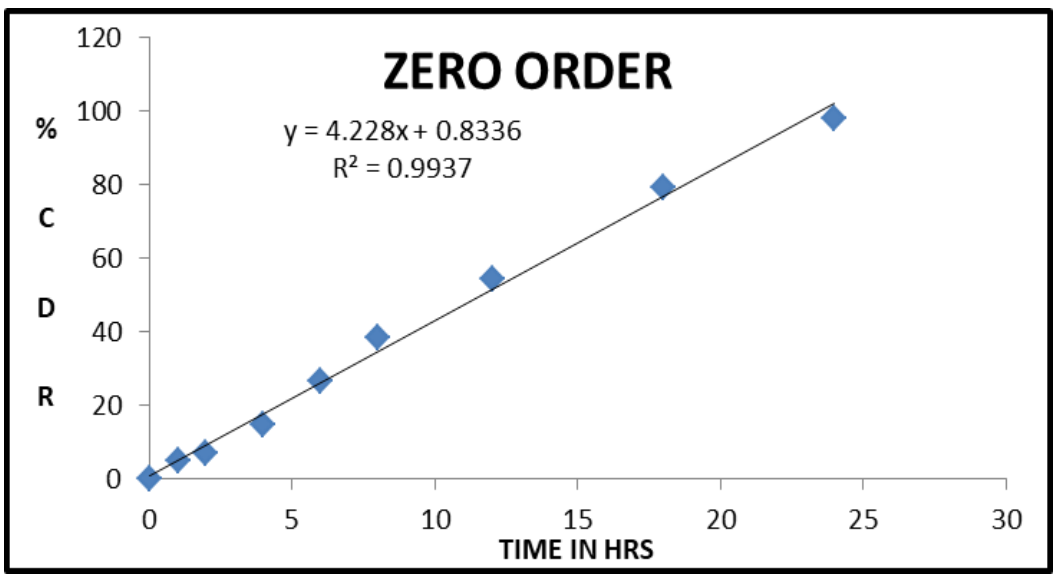

Fig. 9: Zero order plots for optimized formulation T6

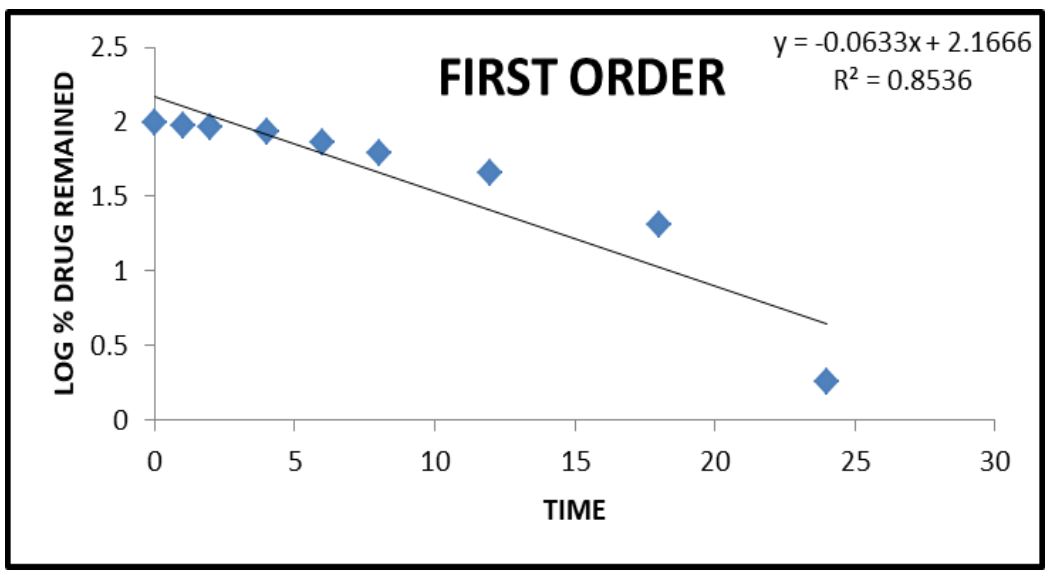

Fig. 10: First order plot for optimized formulation T6

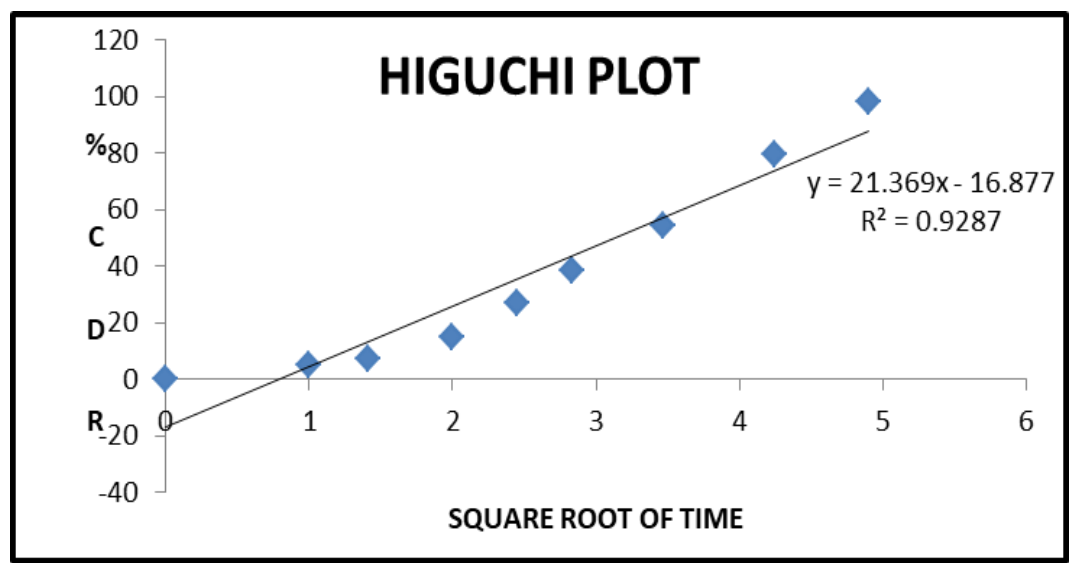

Fig. 11: Higuchi plot for optimized formulation T6 


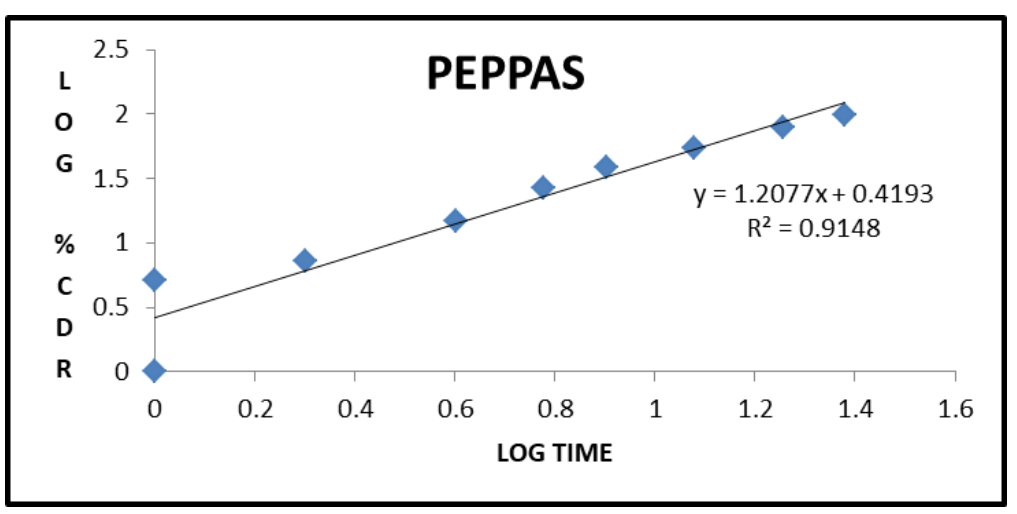

Fig. 12: Peppas plot for optimized formulation T6

\section{CONCLUSION}

An extended release tablet of tramadol was prepared by wet granulation using polymer like hydroxypropyl methylcellulose K100M, K15M and polyethylene oxide (PEO). Based on the stated results of formulation coded T6 shows more sustained action and optimum release than remaining all, which indicates that the concentration of polymer polyethylene oxide was found to play a vital role in controlling the release of tramadol from the matrix system. Accordingly, it can be concluded that the formulation is robust in the performance is less likely to be affected by the various factors studied.

\section{AUTHORS CONTRIBUTION}

All the author have contributed equally

\section{CONFLICTS OF INTERESTS}

The author of this study declared no conflict of interest

\section{REFERENCES}

1. Remington, the science and practice of pharmacy, Lippincott Williams and Wilkins 20th edition; 2002. p. 903-14.

2. Lachmann L, Lieberman HA, Kanig JL. The theory and practice of industrial pharmacy. Varghese Publishing House, Bombay. 3rd Edition; 1991. p. 430-42.

3. Pasa Gourishyam, Mishra Uma Shankar, Tripathy Niraj Kanti, Mahapatra Anjan Kumar, Panigrahi Ghanshyam. Formulation development and evaluation of didanosine sustained-release matrix tablets using HPMC K100. Int Res J Pharm 2011;11:144-6.

4. J Siepmann, NA Peppas. Modeling of drug release from delivery systems based on hydroxyl propyl methylcellulose (HPMC). Adv Drug Delivery Rev 2001;4:139-57.

5. Saptarshi D, Srinivas Rao. Formulation of evaluation of metformin hydrochloride sustained release matrix tablets. J Pharm Res 2010;3:781-9.

6. Tiwari SB, Krishna Murthy T, Raveendra Pai M, Mehta PR, Chowdary PB. Controlled release formulation of tramadol hydrochloride using hydrophilic and hydrophobic matrix system. AAPS PharmSciTech 2003;4:126-32.

7. Vinayak S Modi, Yogesh S Thorat, Shashikant C Dhavale. Formulation and evaluation of controlled release delivery of Tramadol hydrochloride using $3^{2}$-full factorial design. Int J Chem Tech Res 2010;2:669-75.

8. Suryawanshi SS, Shruthi B, Sarvesh, Rama P, Zaranappa S. Sustained release formulations of aceclofenac: a brief review. J Chem Pharm Res 2017;9:302-7.

9. Prasad SR, Ratna KT, Panda S. Formulation development and evaluation of sustained release ibuprofen tablets with acrylic polymers (eudragit) and HPMC. Int J Pharm Pharm Sci 2016;8:131-5

10. Ratnaparkhi MP, Gupta JP. Sustained release oral drug delivery system. Int J Pharm Res Rev 2013;2:11-21.

11. Ariani L, Surini S, Hayun. Formulation of diclofenac sodium sustained release tablet using co-processed excipients of crosslinked amylose-xanthan gum as a matrix. Int J Pharm Pharm Sci 2016;8:151-6.
12. Swain RP, Kumari TR, Panda S. Formulation development and evaluation of sustained release ibuprofen tablets with acrylic polymers (eudragit) and HPMC. Int J Pharm Pharm Sci 2016;8:131-52.

13. Patel NA, Makwana ST, Patel ZP, Solanki SM, Patel MB Formulation and evaluation of once daily sustained release matrix tablet of pramipexole dihydrochloride. Int J Pharm Res Scholars 2012;1:370-82.

14. Ain S, Kumar B, Pathak K. Development and characterization of controlled release famotidine matrix tablets containing complexes. Int J Appl Pharm 2017;9:38-46.

15. Reddy MR, Manjunath K. Pharmaceutical applications of natural gums, mucilage and pectins. Chem Sci 2013;2:1233-91.

16. Joshi K, Dhole S, Doltode A. Formulation and in vitro evaluation of sustained release matrix tablet of dicyclomine hydrochloride by using hydrophilic polymers. Int J Pharm Sci Res 2014;5:1331-81.

17. Sudke SG, Madhusudan RY, Sakarkar DM. Formulation and release behavior of sustain release fenoverine HPMC matrix tablets. Int J Univers Pharm Bio Sci 2013;2:491-500.

18. Asija R, Modi J, Kumawat R, Asija S, Goyal M. Formulation and evaluation of diclofenac sodium sustained release tablets using melt granulation technique. Int J Pediatr 2012;3:216-20.

19. Ramana G, Reddy KD, Sravanthi O. Design and evaluation of natural gum based oral controlled release matrix tablets of ambroxol hydrochloride. DPL 2012;4:1105-14.

20. Ain S, Kumar B, Pathak K. Development and characterization of controlled release famotidine matrix tablets containing complexes. Int J Appl Pharm 2017;9:38-46.

21. Mahajan P, Mahajan SC, Mishra DK. Valsartan release from sustained release matrix tablet and effect of cellulose derivatives. Int J Pharm Life Sci 2011;2:521-30.

22. Patel NA, Makwana ST, Patel ZP, Solanki SM, Patel MB. Formulation and evaluation of once daily sustained release matrix tablet of pramipexole dihydrochloride. Int J Pharm Res Scholars 2012;1:370-82.

23. Jadav MM, Teraiya SR. Formulation and evaluation of oral controlled porosity osmotic pump tablet of zaltoprofen. Int J Pharm Res Scholars 2012;1:254-67.

24. Tapaswi RD, Varma P. Matrix tablets: an approach towards oral extended release drug delivery. Int J Pharma Res Rev 2013;2:12-24.

25. Moses P, Subramanian L, Palanichamy S, Jeganath S, Thanga Thirupathi A. Formulation and evaluation of ciprofloxacin controlled release matrix tablets. DPL 2010;2:237-43.

26. Joshi K, Dhole S, Doltode A. Formulation and in vitro evaluation of sustained release matrix tablet of dicyclomine hydrochloride by using hydrophilic polymers. Int J Pharm Sci Res 2014;5:1331-42.

27. Nair A, Gupta R, Vasanti S. Worked on in vitro controlled release of alfuzosin hydrochloride using HPMC-based matrix tablets and its comparison with marketed product. Pharma Dev Technol 2007;12:621-51.

28. Hosseinali T, Seyed AM, Tina BG. Preparation of sustained-release matrix tablets of aspirin with ethyl cellulose, eudragit RL100, eudragit RS100, and studying the release profiles and their sensitivity to tablet hardness. Iranian J Pharm Res 2003;2:201-6. 
29. Herting MG, Kleinebudde P. Worked on studies on the reduction of tensile strength of tablets after roll compaction/dry granulation. Eur J Pharma Bio Pharma 2008;70:372-91.

30. Saravanan M, Sri Nataraj K, Ganesh KS. worked on hydroxypropyl methylcellulose-based cephalexin extendedrelease tablets: influence of tablet formulation, hardness and storage on in vitro release kinetics. Chem Pharma Bull 2003;51:978-83.

31. Uhum wangho MU, Okor RS. Worked on modification of drug release from acetaminophen granules by melt granulation technique-consideration of release kinetics. Pak J Pharma Sci 2006;19:22-7.

32. Raghavendra Rao NG, Gandhi Sagar, Patil Tarun. Formulation of evaluation of sustained release matrix tablets of tramadol hydrochloride. Int J Pharm Pharm Sci 2009;1:60-70.
33. Shanmugam S, Kamaraj K, Vetrichelvan T. Formulation and evaluation of lamivudine sustained release matrix tablets using synthetic polymers. J Pharm Res 2012;5:1063-6.

34. The United States Pharmacopoeia/National Formulary, USP 37/NF 32. Vol. I. The United States Pharmacopoeial Convention, Timbrook Parkway, Rockville; 2014. p. 344-61.

35. Bhosale RR, Riyaz AM, Osmani PC, Moin A. Formulation and evaluation of sustained release dosage form using modified cashew gum. Int J Pharm Pharm Sci 2015;7:141-50.

36. Kambham V. Formulation and evaluation of sustained release matrix tablets of repaginate. Bangladesh Pharma J 2016;19:92-9.

37. Moses P, Subramanian L, Palanichamy S, Jeganath S, Thanga Thirupathi A. Formulation and evaluation of ciprofloxacin controlled release matrix tablets. DPL 2010;2:237-43.

38. Patel R, Baria A. Formulation development and process optimization of theophylline sustained release matrix tablet. Int J Pharm Pharm Sci 2009;1:30-42. 